\title{
¿EL EMPERADOR HERACLIO COMO NUEVO DAVID? \\ LA ICONOGRAFÍA DE LOS PLATOS BIZANTINOS DE CHIPRE FRENTE A LAS FUENTES ESCRITAS
}

\author{
JOAQUÍN SERRANO DEL POZO. \\ PONTIFICIA UNIVERSIDAD CATÓLICA DE VALPARAÍSO, Chile.
}

\begin{abstract}
Resumen: Los "Platos de Chipre" o "Platos de David", han sido objeto de interesantes interpretaciones y debates académicos. El principal problema es si estos platos, fabricados en época de Heraclio (610-641), pueden vincularse de algún modo a este emperador. El análisis de la iconografía de los platos en contraste con varias fuentes escritas arroja cierta luz sobre este asunto, sugiriendo que la historia de David representada en ellos puede haber sido vista en la época como una alusión a la figura de Heraclio.
\end{abstract}

Palabras clave: Bizancio- Siglo VII - Heraclio - Iconografía - Platos de Chipre - Platos de David

\section{¿THE EMPEROR HERACLIUS AS A NEW DAVID? \\ THE ICONOGRAHY OF THE BYZANTINE PLATES OF CYPRUS AGAINST THE WRITTEN SOURCES.}

\begin{abstract}
The "Cyprus Plates" or "David Plates" have been the focus of significant researches and academic quarrels. The main issue is whether these plates, made at the time of Heraclius (610-641), can be linked in some way to this emperor. The analysis of the iconography of the plates in contrast to several written sources sheds some light on this question, suggesting that the story of David represented in them may had been perceived at the time as a reference to the figure of Heraclius.
\end{abstract}

Keywords: Byzantium - Seven century - Heraclius - Iconography - Cyprus Plates - David Plates

Recibido: 30.03.2016 - Aceptado: 1.06.2016

Correspondencia: Joaquín Serrano del Pozo.

Email: serranojoaquin91@gmail.com

Profesor del Diplomado en Civilización y Cultura Medieval / Grupo de estudios Circulación de la Información, objetos y personas. Pontificia Universidad Católica de Valparaíso, Chile. Licenciado en Historia / Candidato a Magister en Historia. Pontificia Universidad Católica de Valparaíso, Chile. 7 norte 1401 (depto. 1506) Viña del Mar, Chile. Cel: +56989865465 . 
$\mathrm{L}$ os "Platos de Chipre" o "Platos de David" son una serie de nueve discos bizantinos de plata, de distintos tamaños y grabados con varias imágenes, que fueron descubiertos en Karavas, en el norte de Chipre, en 1902. Actualmente seis de estos platos se encuentran en el Museo Metropolitano de Arte de Nueva York y los otros tres en el Museo Arqueológico de Nicosia, Chipre ${ }^{1}$.

Estos platos representan la historia bíblica de David en diversos episodios, desde sus orígenes pastoriles hasta su matrimonio con la hija de Saúl. El más grande de estos representa el famoso combate de David contra Goliat. En el reverso de los platos puede encontrarse el sello del emperador Heraclio, que acredita la pureza de su plata. Su elaboración se ha datado cercana a los años 629/630 d.C. No se tiene certeza respecto a su lugar de origen pero, por su material y factura, deben haber pertenecido a un contexto cortesano o aristocrático. Es probable que se los haya utilizado en ceremonias y banquetes oficiales, desplegados de forma tal que los platos medianos y pequeños rodeen al más grande y sigan el orden bíblico de los eventos con el combate en el centro. No se sabe si siempre estuvieron en Chipre o cómo llegaron a la Isla, se cree que fueron enterrados con otros tesoros como medida desesperada ante la invasión árabe de las islas (c. 653 d.C. $)^{2}$.

El origen, funcionalidad e interpretación de los Platos de David han suscitado muchos debates entre los especialistas. Este trabajo pretende recoger dicha discusión y volver sobre ella, analizando algunos aspectos de la iconografía de estos en contraste con varias fuentes escritas. El objetivo es ofrecer una nueva propuesta explicativa sobre los Platos de Chipre, considerando los distintos niveles de significación, lectura e interpretación de las imágenes bizantinas y aproximándose a las posibilidades que estas ofrecen al historiador para comprender la cultura de la época.

André Grabar, en los años treinta, fue uno de los primeros en proponer una interpretación sobre la iconografía de estos platos-más allá de la identificación del contenido bíblico de los mismos-señalando la posibilidad de que el anónimo artista de los Platos de David quizás buscaba insinuar mediante su obra un paralelismo entre el emperador Heraclio (610-641) y la figura

1 Morales, E.; Norris, M.; Schwarz, A.; Watts, E. (2001). A Masterwork of Byzantine Art. The David Plates: The Story of David and Goliath, The Metropolitan Museum of Art, New York, p.7. Imágenes en el sitio web del Museo Metropolitano de Arte de Nueva York: http://www.metmuseum.org/collection/the-collection-online/ search/464377 (25-11-2015).

2 Morales, E.; Norris, M.; Schwarz, A.; Watts, E. (2001).pp. 7-13. 
bíblica del rey David ${ }^{3}$. Durante muchos años esta sugerencia no fue rebatida ni profundizada por ningún estudio especializado, pero a partir de los años setenta varios especialistas retomaron el problema, generando un debate que sigue existiendo hasta la actualidad.

El primer estudio especializado sobre la iconografía de estos platos fue el realizado por Kurt Weitzmann en 1970, quien rastreó las fuentes iconográficas de los mismos señalando que estos pudieron haberse inspirado en las representaciones de la historia de David de algunos manuscritos, pero sin pronunciarse sobre el paralelismo con Heraclio ${ }^{4}$.

En 1973 Steve H. Wander realizó una lectura iconográfica de los nueve ejemplares, vinculando directamente su contenido con varios pasajes bíblicos concretos de la historia de David 5 . Propuso que la iconografía de los platos estaría orientada a exaltar la figura de David como un elegido y campeón de Dios. Señaló que, aunque existen algunos modelos de inspiración, los platos parecen ser una creación original y que-por el increíble valor de la pieza- deben haber sido realizados en Constantinopla como regalo $\mathrm{u}$ ofrenda para un alto dignatario imperial, probablemente para el propio emperador Heraclio (610$641)^{6}$.

Wander planteó que el combate entre David y Goliat podría ser una alusión a un episodio "histórico" de la época: el combate entre Heraclio y el general persa Razates narrado por la Historia syntomos del Patriarca Nicéforo y aludido en otras fuentes de la época. Pese a que la mayoría de estas fuentes son tardías y que la descripción de los combates no calce exactamente, Wander señaló que la victoria de David sobre el filisteo Goliat podría haber servido para exaltar el triunfo del emperador Heraclio sobre los persas ${ }^{7}$. Dos años después, en un breve artículo, Wander re-afirmó esta idea a partir de un testimonio franco del siglo VII, la Crónica de Fredegario, que narra también el combate entre Heraclio y un "patricio" de los persas ${ }^{8}$.

3 Grabar, A. (1936). L'Empereur dansl'art Byzantin, Les Belles Lettres, París, pp. 96-97.

4 Weitzmann, K. (1970). "Prolegomena to a Study of the Cyprus Plates", Metropolitan Museum Journal, 3, pp. 97-111. Existían ya otros estudios especializados sobre aspectos materiales, de datación o estilo.

5 Wander, S. H. (1973). "The Cyprus Plates: The Story of David and Goliath" Metropolitan Museum Journal, 8, pp. 89-95.

$6 \quad$ Ibíd. pp. 97-103.

$7 \quad$ Ibíd pp. 103-104.

8 Wander, S.H. (1975). "The Cyprus Plates and the Chronicle of Fredegar", Dumbarton Oaks Papers, 29, pp. 345-346. 
Esta línea de argumentación fue profundizada por los estudios de Mariette Van Grunsven Eygenraam, Suzanne Spain Alexander y John Trilling, quienes vincularon los platos a la figura de Heraclio, proponiendo que el emperador fue quien los mandó a hacer y que estos evocaban ciertos episodios de su reinado, como su ascenso al poder o sus victorias en la guerra ${ }^{9}$. Los platos habrían sido regalados a un alto dignatario imperial o eclesiástico, pero habrían actuado también como objeto de propaganda del propio Heraclio ${ }^{10}$.

Particularmente interesante es el artículo de Suzanne Spain en donde planteó que los Platos de Chipre no solo establecían una asociación entre la figura del rey David y el emperador Heraclio, sino que estos podían datarse en el período posterior a la guerra contra Persia (628-630), en donde el emperador comenzó a preocuparse por su imagen debido a las acusaciones por el matrimonio con su sobrina, a las querellas religiosas y a la aparición de nuevas amenazas en las fronteras. Durante estos años, el emperador Heraclio-mediante sus actos y su aparato de propaganda- buscó reforzar la imagen de sí mismo como un "nuevo David", paralelismo habitual en Bizancio y que ya había sido planteado por algunos clérigos y poetas en los años previos, pero que cobraría todo un nuevo sentido tras la victoria en la guerra contra Persia, la recuperación de la "Santa Cruz" y otros hechos de la época".

Estos trabajos de los años setenta establecieron una corriente interpretativa que explicaba los Platos de Chipre en base al contexto político de su época y los vinculaba con la figura del emperador Heraclio. Durante varios años esta forma de interpretación fue aceptada casi sin cuestionamientos, hasta el año 2000 cuando Ruth. E. Leader-especialista en objetos de plata de la Antigüedad Tardía- publicó un artículo al respecto.

Ruth. E. Leader postuló que los Platos de David no deben ser vistos como un objeto de propaganda imperial, sino como vajilla de lujo con motivos bíblicos, que responde al proceso de cristianización del espacio domestico de la época. Leader señaló que el único vínculo concreto entre los platos y Heraclio es el sello de pureza que tienen en el reverso, pero que este no indica que los platos fueran encargados por él mismo o destinados a su uso personal, además

$9 \quad$ Van Grunsven Eygenraam, M. (1973). "Heraclius and the David Plates", Bulletin Antieke Beschaving, 48, pp. 158-174; Spain, S, (1977). "Heraclius, Byzantine Imperial Ideology, and the David Plates", Speculum, 52, No. 2, pp. 217-237; Trilling, J. (1978). "Myth and Metaphor at the Byzantine Court: A Literary Approach to David Plates", Byzantion, 48, pp. 249-263.

10 Van Grunsven Eygenraam, M. (1973). p. 174.

11 Spain, S. (1977). pp. 217-237. 
de no existir otros ejemplos de representaciones imperiales similares en la época. Vincular eventos de la vida de Heraclio con la historia de David sería aventurado, puesto las fuentes de la época no llevan el paralelismo HeraclioDavid a episodios concretos, la idea del emperador como "nuevo David" sería un prototipo ideal y atemporal en Bizancio. Además no todas las imágenes de los platos pueden relacionarse a la vida Heraclio, ni es muy claro que el David de los platos este representado a modo de emperador. Finalmente, Leader compara los Platos de Chipre con objetos de plata de siglos anteriores que son bastante similares pero llevan motivos clásicos y que eran claramente utilizados como vajilla de lujo, proponiendo que muchos de estos platos representaban motivos heroicos asociados a la paideia clásica, como la historia de Aquiles. Estos platos se explicarían entonces como parte de la cristianización del arte en los contextos domésticos que se estaba produciendo en la época, en donde los temas de la paideia clásica son remplazados por motivos bíblicos ${ }^{12}$.

¿Cómo interpretar entonces los Platos de Chipre? ¿Cuál es su sentido y significado? ¿Existe una vinculación clara entre estos y la figura del emperador Heraclio? ¿Se trata simplemente de vajilla doméstica de lujo decorada con motivos cristianos o de arte de propaganda imperial? No es un problema sencillo, pero intentaremos abordarlo considerando primero el paralelismo general Heraclio-David en las fuentes de la época y luego analizando las representaciones de los platos en base a estos referentes.

No son muchas las fuentes escritas estrictamente contemporáneas al emperador Heraclio, en el ámbito de la historiografía el autor más destacable es Teofilacto Simocates, pero este, aunque escribe en tiempos de Heraclio, dedica su obra al gobierno del emperador anterior: Mauricio. La otra fuente historiográfica contemporánea que se ha conservado es el anónimo Chronicon Paschale, una crónica de Constantinopla que registra en forma cronológica y lacónica varios acontecimientos del período, fuente invaluable pero que no ofrece muchas luces sobre nuestro problema de estudio ${ }^{13}$. Sin embargo, un ámbito mucho más propicio es el de la literatura secular y religiosa de la época.

Una de las fuentes más interesantes del gobierno de Heraclio son

12 Leader, R. E. (2000). "The David Plates Revisited: Transforming the Secular in Early Byzantium", The Art Bulletin, 82, No. 3, pp. 407-424.

13 Howard-Johnston, J. (2010). Witnesses to a world crisis. Historians and Histories of the Middle East in the Seventh Century, New York, Oxford University Press, pp. 36-69. El único aspecto interesante del Chronicon Paschale ya lo señaló Suzanne Spain: la carta en donde Heraclio presenta su guerra con Persia como un justo castigo contra los paganos y así mismo como siervo de Cristo. Spain S. (1977), "Heraclius...", pp. 221-222. 
los poemas de Jorge de Pisidia: clérigo y poeta proveniente de Antioquía en Pisidia-Asia Menor-, comenzó a escribir poesía llamando la atención del emperador cerca del año 622 y llegó a convertirse en el poeta oficial de la corte hasta su muerte (c. 632). Jorge de Pisidia acompañó a Heraclio en varias de sus campañas militares y es posible que estableciera con él una relación de amistad. $\mathrm{Su}$ obra se compone de distintos poemas panegíricos, épicos y religiosos, la mayoría de ellos exaltan la figura de Heraclio o conmemoran hechos puntales de su gobierno: la sublevación contra Focas, la guerra contra los avaros, las campañas persas y la famosa recuperación de la $\mathrm{Cruz}^{14}$.

La poesía de Jorge de Pisidia se ha considerado panegírica pues presenta continuamente a Heraclio como un emperador cristiano ideal: justo, valiente y piadoso. Para ello interpola tanto referencias clásicas como bíblicas. En el poema de las campañas persas de Heraclio, la Expeditio Persica, esto alcanza su máxima expresión en la figura de un emperador que es considerado un campeón elegido de Dios, valiente lugarteniente de sus ejércitos y humilde soldado de Cristo $^{15}$. En el poema que conmemora la restitución de la Santa Cruz en Jerusalén -recobrada de los persas mediante la guerra- pueden verse varias alusiones de este tipo, en donde se compara a Heraclio con Constantino y se le alaba por derrotar a los bárbaros paganos, pero también se compara la Cruz restaurada con el Arca de la Alianza ${ }^{16}$.

La idea del emperador como campeón elegido de Dios tiene una clara reminiscencia a los reyes del Antiguo Testamento. Pero las alusiones veterotestamentarias son mucho más explícitas y evidentes en otro texto de la época: la homilía escrita por Teodoro Synkellos sobre el sitio de Constantinopla del 626. Poco se sabe de este Teodoro, excepto que era un eclesiástico que ostentaba el cargo de Synkellos: responsable de las relaciones entre el poder civil y el patriarcado, y al que en el año 626 el patriarca le encomendó redactar un sermón religioso en relación al sitio ávaro-persa de la capital. Esta homilía es un documento importante para conocer los sucesos históricos asociados al sitio del 626, pero aquí interesa principalmente por desplegar una retórica y un imaginario que vinculan la época de Heraclio, al emperador y sus guerras, con el Antiguo Testamento.

14 Pertusi, A. (1959).Giorgio di Pisidia poemi i Panegirici epici, Ettal, BuchKunstverlag (ver el estudio introductorio). Howard-Johnston, J. (2010).pp. 16-35.

15 Jorge de Pisidia, Expeditio Persica III, en 3: 1-75. pp. 115-119, 3: 80-145. pp. 118-122, 3: 250-255. p. 127, 3: 385-405. p. 133. En Pertusi, A. (1959). Por señalar solo algunos ejemplos.

16 Jorge de Pisidia, In restitutionem S. Crucis. 47-63, 70-80, pp. 227-228. 
Justamente, la Homilía de Synkellos desarrolla su relato del sitio del 626 con un continuo paralelismo entre los eventos contemporáneos y el Antiguo Testamento: los romano-cristianos son el nuevo Israel, el pueblo elegido; Constantinopla es la nueva Jerusalén; el Patriarca es el Nuevo Moisés, ávaros y persas son homologados a los enemigos de Israel, Gog y Magos, etc...Para nuestro tema, lo más interesante es que el emperador Heraclio es explícitamente presentado como el Nuevo David ${ }^{17}$. Además, la Homilía interpreta que la victoria en la resistencia al sitio se debe a que Dios combate del lado de los romanos y, en particular, a la Madre de Dios (Theotókos) quien habría intervenido directamente en el asedio como protectora sobrenatural de la ciudad $^{18}$.

El paralelismo entre Heraclio y David aparece de forma implícita en la poesía panegírica de Jorge de Pisidia, en donde aparece como campeón de Dios al modo de los antiguos reyes de Israel, y de forma explícita en la Homilía de Synkellos, en donde se habla de Heraclio como "Nuevo David". Pero además, estos textos y otros similares -escritos en la misma época o algunas décadas después- hablan de un contexto marcado por una fuerte efervescencia escatológica, en donde la cadena de eventos presentes parece estar prefigurada en las Sagradas Escrituras, anunciando que se vive la plenitud de los tiempos $\mathrm{y}$ el fin es inminente ${ }^{19}$. Los escritos del Patriarca Sofronio, la Caída de Jerusalén de Antíoco Estratego, el Apocalipsis de Zorobabel, el Libro de Elías, la traducción siríaca del Pseudo Calístenes, y la historia armenia atribuida a Sebeos interpretaron en esta línea la guerra romano-persa y otros sucesos de la época de Heraclio ${ }^{20}$.

Pablo Ubierna ha analizado cómo esta efervescencia escatológica fue promovida y utilizada políticamente por distintos actores, entre ellos la corte de Constantinopla y el propio Heraclio. En esta línea surge la "leyenda del último emperador", propaganda imperial-escatológica que reinterpretaba los

$17 \quad$ Teodoro Synkellos, Homilía sobre el sitio de Constantinopla del año 626. Traducción al castellano inédita del profesor José Marín R. en base a Makk, F. (1975). "Traduction et Commentaire de l'Homélieé crite probablement par Théodore le Syncelle sur le Siège de Constantinople en 626", Acta Universitatis de Attila József Nominatae, Opuscula Byzantina III, Szeged, pp. 9-47.

18 Marín Riveros, J. (2011). "Bizancio en el siglo VII: Entre historia y profecía. Notas en torno a los sucesos del año 626”, Byzantion Nea Hellás, 30, pp. 41-73.

19 Ibíd. pp. 54-66.

20 Ubierna, P. (2008). "Recherches sur l'apocalyptique syriaque et byzantine au vii siècle: la place de l'Empire romain dans une histoire du salut", Bulletin du centre d'études médiévales d'Auxerre, Horssérie $\mathrm{n}^{\circ} 2$. 
textos bíblicos para sostener que antes de la segunda venida de Cristo habría de triunfar un gran emperador cristiano, verdadero campeón de Dios que establecería un largo y duradero reinado de paz $^{21}$. Como han señalado varios autores, esta búsqueda de legitimidad podría deberse a las iniciales derrotas en la guerra, a las críticas por el matrimonio con su sobrina y a otros problemas del Imperio ${ }^{22}$. Por ello Heraclio habría buscado presentarse a sí mismo como "nuevo Constantino" y "nuevo David" a través de la literatura y de actos públicos como la famosa restitución de la "Santa Cruz" en Jerusalén.

Por tanto, en la época de Heraclio, y en las décadas posteriores, el paralelismo retorico entre este emperador y la figura de David era muy común. Es cierto que, como señala Ruth E. Leader, la imagen de un "nuevo David" es un tópico recurrente entre los emperadores bizantinos y muchos otros soberanos medievales. Sin embargo, en la época de Heraclio esta imagen no solo fue particularmente frecuente, sino que además adquirió una fuerza y sentido inéditos a partir del contexto de guerra contra los persas y de efervescencia escatológica antes explicado ${ }^{23}$.

Ahora bien, la tesis que sostiene que los Platos de David son un instrumento de propaganda imperial se basa también en la identificación de algunos motivos de los platos con ciertos episodios de la vida de Heraclio, particularmente el combate de David y Goliat ${ }^{24}$. Es necesario revisar esta idea.

El plato central está dividido en tres escenas, en la parte superior David confronta a Goliat, desde el cielo la mano de Dios lo apunta señalándolo como su elegido, entre medio de ambos aparece una figura que parece ser una personificación del río de donde David toma las piedras para su honda. La escena central, que es la más grande, representa directamente el combate,

21 Ubierna, P. (2002). "La «leyenda del Último Emperador» en Bizancio y el Cercano Oriente cristiano (ss. VII-X). Una instrumentalización del género apocalíptico", Los caminos inexhauribles de la Palabra, Buenos Aires, LUMENISEDET, pp. 463-493.

22 Spain, S. (1977). pp. 225-227.

23 Es justamente este contexto marcado por un fuerte imaginario épico-religioso e interpretaciones escatológicas, y particularmente la imagen ofrecida por la literatura de Jorge de Pisidia, lo que ha llevado a muchos autores a hablar de las guerras de Heraclio como guerras santas, religiosas o incluso un antecedente de las cruzadas. Desde el cronista medieval Guillermo de Tiro hasta historiadores contemporáneos como Steve Runciman. Ver: Marín Riveros, J. (2003). Cruzada, guerra santa y yihad. Ed. Universitaria de Valparaíso, Valparaíso, pp. 91-97. Runciman, S. (1977). The Byzantine Theocracy, CUP, Cambridge, pp. 54-55. Frolow, A. (1955). Reserches sur la Déviation de la Ive Croisade vers Constantinople, PUF, París, pp. 72 y ss.

24 Wander, S. H. (1973). p. 103. 
Goliat avanzando con la lanza levantada y David preparando la honda, detrás de David las tropas israelitas avanzan mientras al otro lado los filisteos parecen huir. En la escena inferior un David victorioso decapita a Goliat ${ }^{25}$.

\section{Imagen $\mathbf{1}^{26}$}

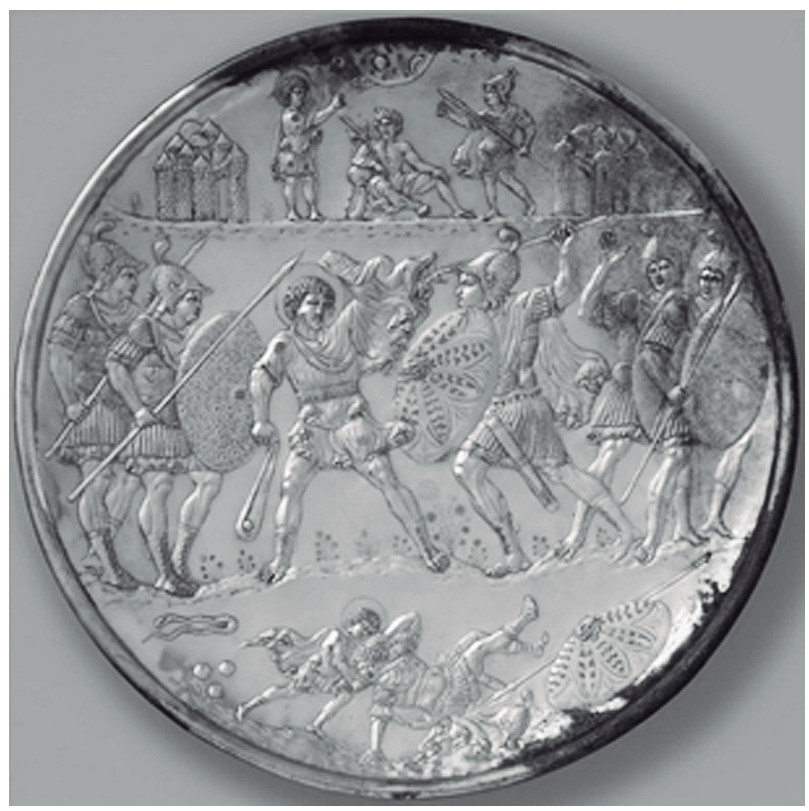

Esta imagen se ha relacionado con un supuesto episodio de las campañas de Heraclio en donde el emperador habría luchado en un duelo singular contra un general persa. Steve H. Wander señala que este combate es narrado por Nicéforo y que probablemente también habría sido relatado por Jorge de Pisidia en unos versos que se han perdido. También menciona otras fuentes, como el Pseudo Sebeos y Teófanes, aunque no profundiza en ellas. ${ }^{27}$ Además, en otro artículo complementa esta idea aludiendo a un relato similar en la Crónica de

$25 \quad$ Morales, E.; Norris, M.; Schwarz, A.; Watts, E. (2001). p. 12.

26 "Plate with the Battle of David and Goliath" (629-30). Museo Metropolitano de Arte de Nueva York. Código: 17.190.396. URL estable: http://www.metmuseum. org/collection/the-collection-online/search/464377 (25-11-2015)

27 Wander, S. H. (1973). p. 103. 
Fredegario $^{28}$. Pero el apoyo documental utilizado por Wander, aunque pueda parecer contundente, si se analiza bien, es bastante problemático. Puesto que, la única fuente bizantina en donde efectivamente se describe con claridad un combate entre el emperador Heraclio y un guerrero persa es la Historia Breve del patriarca Nicéforo:

Cuando Cosroes fue informado de que Heraclio se encontraba cerca de la residencia real persa, envió contra él un general bravo y experimentado llamado Razates. Este hombre colocó [sus fuerzas] frente al emperador y, avanzando delante de sus líneas, lo desafió a un duelo. Cuando Heraclio se dio cuenta de que ninguno de sus hombres se presentaría voluntario, fue por él mismo contra el bárbaro. Siendo [Razates] un arquero experto, disparó una flecha que rozó el labio del emperador. Luego disparó una segunda flecha que arañó su tobillo. Entonces Heraclio apuró su caballo, y un hombre de su guardia, que se adelantó a él, hirió con su espada el hombro de Razates; y cuando este hubo caído, el emperador lo atravesó con su lanza e inmediatamente le cortó la cabeza. Al ver esta victoria, el ejército romano se llenó de ardor. Percatándose de la audacia del emperador, avanzaron enérgicamente contra los persas, a quienes derrotaron completamente y luego persiguieron, exterminando un gran número de ellos ${ }^{29}$.

Desde el punto de vista literario, existen claramente algunos aspectos de este relato que pueden vincularse a la imagen del combate de David y Goliat en los "Platos de Chipre". En ambos casos se trata de un duelo singular, en el contexto de una batalla, un guerrero de cada ejército se adelanta para enfrentarse al otro. Desde el punto de vista del desarrollo del combate y las armas elegidas no existe mucha semejanza, pues David mata a Goliat sin ayuda y utilizando una honda. Respecto al final, en ambos casos el vencido es decapitado y el combate es seguido por la derrota y persecución del ejército enemigo ${ }^{30}$. El relato de Nicéforo no compara a Heraclio con David ni tampoco parece presentarlo como un campeón o elegido de Dios, aunque existen algunas semejanzas que

$28 \quad$ Wander, S. H. (1975). pp. 345-346.

29 Nicéforo, Historia Breve, 14:1-17. En Mango, Cyril. (1990). Nikephoros, patriarch of Constantinople, Short History, Washington D.C., Dumbarton Oaks, pp. 60-61. Traducción propia a partir de la versión bilingüe griego-inglés de Cyril Mango. 30 Samuel I. 17: 40-55. En Biblia de Jerusalén. (1992). Desclee de Brouwer, Bilbao. 
quizás podrían haber llevado a un contemporáneo a evocar al episodio a partir del plato central.

Ahora bien, el principal problema es que la Historia Breve de Nicéforo fue redactada entre los años 770-820 aproximadamente, es decir, más de ciento cuenta años después del gobierno de Heraclio y de la elaboración de los platos $^{31}$. Para el propósito de este trabajo no importa realmente si el episodio del combate sucedió o no, pero sí que la historia haya sido conocida por los contemporáneos, pues de tratarse de una leyenda tardía, no tendría cabida en estos platos.

Wander señala que esta historia sería relatada también en un poema de Jorge de Pisidia -quien sí era contemporáneo de Heraclio y de los Platos- pero que los versos de dicho poema estarían perdidos. L. Sternbach postuló que existía un amplio cuerpo de poemas, algunos de ellos referidos a episodios de la guerra contra Persia, que se perdieron. Sabemos de estos poemas porque algunos de sus versos son mencionados o incluso citados en obras posteriores, el cronista Teófanes claramente incorporó algunos de estos versos en su obra historiográfica $^{32}$. En base a Teófanes y otros textos se han reconstruido fragmentos de un poema sobre la campaña persa ${ }^{33}$. Según Wander existió una parte que habría narrado el duelo con Razates pero que se ha perdido totalmente. Esta suposición es bastante problemática, pues casi nada, excepto el texto de Nicéforo, permite suponer que Pisides habría narrado tal combate. Es cierto que, a lo largo de sus poemas, Pisides presenta a Heraclio como un heroico campeón de Dios, un general valiente y humilde, que acompaña siempre a sus soldados y lucha junto a ellos en la primera línea de la batalla ${ }^{34}$. Pero en toda su obra poética, tanto en los poemas íntegros como en los fragmentos, no existe ninguna referencia clara a un duelo con un general persa.

Además los poemas de Pisides suelen utilizar un lenguaje muy alegórico. Por ejemplo, uno de ellos dice que Heraclio "Se mostró como un héroe cuando escapándose de sus garras, dio muerte al dragón, no con los venenos de Medea, sino atravesándolo con el Santo Leño"35.

31 Howard-Johnston, J. (2010).pp. 238-250.

32 Pertusi, A. (1959). pp. 17-31.

33 Ibíd. pp. 276-307.

34 Jorge de Pisidia, Expeditio Persica III, 3: 1-145. pp. 115-122.

35 Jorge de Pisidia, In restitutionem S. Crucis. II. 20-25. "Un eroe ti mostrasti strappando dagliartigli del drago uccisoil vello d' oro i veleni di Medea, matrafiggendolo con il (S.) Legno" 
¿Qué representa este verso? ¿Un enfrentamiento con Cosroes, Razates, el reino persa o el demonio? Frente a este tipo de textos es imposible especular sobre una descripción del combate sin tener el fragmento concreto, pues asumiendo que este existe podría tratarse tanto de un episodio histórico como de una metáfora -lucha eterna del bien contra el mal- frecuentes en la obra de Pisides. Por ello, estos poemas, aunque no sean descartables, no son prueba suficiente para saber que la historia de este combate circulaba en el siglo VII. Pero ¿qué otra documentación existe? Wander alude al Pseudo Sebeos y Teófanes.

La historia atribuida a Sebeos, es una obra escrita en Armenia aproximadamente entre los años 650-660 -es decir, solo una o dos décadas posteriores al tiempo de Heraclio- por un clérigo cristiano del lugar, quizás un obispo. Escrita en armenio y desde una perspectiva un tanto local, su principal foco es la guerra romano-persa y el enfrentamiento entre el emperador Heraclio y el rey persa de Cosroes II, "maldito por Dios"36.

Wander menciona al Pseudo-Sebeos como otro de los cronistas que supuestamente hablan de este duelo, pero si se revisa detenidamente la Historia armenia, no se encuentra nada tan explícito, lo único que dice esta fuente es que en la batalla final contra los persas:

...Heraclio los llevó hasta la planicie de Nínive y luego los atacó con una gran fuerza. Había niebla sobre la planicie, y el ejército persa no se dio cuenta de que Heraclio se había vuelto contra ellos hasta que se encontraron con él.

De esta manera el señor demostró su misericordia, porque Heraclio ese día, los había masacrado hombre a hombre, y matado a su general en el campo de batalla... ${ }^{37}$.

Este fragmento continua señalando cómo Heraclio perdonó la vida a los persas sobrevivientes, efectivamente señala que Heraclio mató a su general en el campo de batalla, pero en ningún momento dice que esto haya sido parte de un combate singular, el texto sugiere que acabó con él en el fragor de la propia batalla. Ahora bien, la historia del combate podría ser una tradición que se fue volviendo legendaria y transformando con el tiempo. ¿Cuál es la otra

$\overline{36}$ Thomson, R.W; Howard-Johntson, J. (1999).The Armenian History attributed to Sebeos. Liverpool, Liverpool University Press. Introducción, pp. XXXI-XLVII.

$37 \quad$ Ibíd. Cap 38 [126], p. 84. Traducción propia a partir de la versión en inglés de R.W Thomson. 
fuente mencionada por Wander? La Cronografía de Teófanes.

Teófanes el Confesor (759/60-818) fue un aristócrata bizantino, muy bien formado intelectualmente que tomó votos monásticos en su vejez y vivió sus últimos años de forma ascética. Escribió su Cronografía como una continuación de la crónica universal de su amigo Jorge Sincelo, quien se la pidió al darse cuenta que no podría terminarla. Teófanes extendió dicha crónica desde el año 284 d.C. hasta el 813. Esta obra sigue el esquema general del género cronístico y es, sobre todo, un trabajo de compilación de documentos anteriores antes que una composición puramente original ${ }^{38}$. La obra de Teófanes, es por tanto, aún más tardía que la de Nicéforo y por ello tampoco puede demostrar que la historia del combate de Heraclio circulase en el siglo VII. Además en Teófanes tampoco existe ninguna mención explícita a un duelo singular contra Razates, aunque si se relatan ciertos episodios de combate en medio de batallas, como el de la batalla en torno al río Saros cuando:

Un hombre gigante enfrentó al emperador en el medio del puente y lo atacó, pero el emperador arremetió contra él y lo arrojó al río. Cuando este hombre cayó, los bárbaros se dieron a la huida // y, debido a la estrechez del puente, saltaron en el río como ranas // mientras otros eran exterminados por la espada (...) el emperador cruzó al otro lado y audazmente se opuso a los bárbaros con unos pocos hombres de su guardia ${ }^{39}$.

Sin embargo, un episodio aún más significativo es relatado cuando las fuerzas persas del general Razates son enviadas por Cosroes a enfrentarse contra Heraclio y, en medio del combate:

El emperador cargó al frente de todos y se encontró con el comandante de los persas y, con el poder de Dios y la ayuda de la Madre de Dios, lo abatió, y aquellos que habían avanzado con él retrocedieron. Entonces el emperador se encontró con otro persa en combate y también lo derribó. Hasta un tercero lo atacó y alcanzó con una lanza, hiriendo su labio, pero el emperador acabó con él también ${ }^{40}$.

38 Mango, C; Scott, R (1997). The Chronicle of Theophanes Confessor. Oxford, Clarendon Presss, pp. XLIII-LXXIV., y Howard-Johnston. (2010). pp. 270-274.

39 The Chronicle of Theophanes Confessor.313-314 (AM 6116). pp. 444-445. Traducción propia a partir de la versión de Cyril Mango y Roger Scott. 
Por tanto, Teófanes también recoge la historia de un combate en donde Heraclio se enfrenta al comandante de los persas - posiblemente Razates- y lo abate, no en un duelo sino en medio de la batalla. Al igual que en la obra de Nicéforo, Heraclio es herido en el labio. Además, Teófanes recoge la historia de un combate contra un gigante - ¿Goliat?- cuya derrota produce la huida de los enemigos. Se ha especulado que estos pasajes podrían estar tomando versos perdidos de Jorge de Pisidia, pero como veíamos esto no puede ser confirmado con certeza ${ }^{41}$. Teófanes es una fuente muy tardía y podría estar influenciado por el propio Nicéforo, pero da cuenta de la circulación de diversas historias sobre un combate de Heraclio.

Dos años después de su primer trabajo sobre el tema, Wander publicó un breve artículo en donde reafirmó su tesis en base a una fuente occidental: la Crónica atribuida a Fredegario ${ }^{42}$.

Obra escrita en latín cerca del año 660en el sureste de Francia y mal atribuida en el siglo XVI a un supuesto Fredegario. Fue redactada por un clérigo anónimo que compiló crónicas anteriores y agregó material de su propia mano para los tiempos recientes. Posteriormente, la crónica fue continuada por otros autores, pero esa continuación hoy se considera una obra distinta ${ }^{43}$. Es una fuente cercana a los tiempos de Heraclio pero bastante alejada geográfica y culturalmente del ámbito bizantino. Sin embargo, esta crónica pretende ser universal y por ello hace continuas referencias a Bizancio, relata brevemente la guerra romano-persa y cuenta que cuando los ejércitos de ambos bandos se encontraron:

Mediante embajadores, Heraclio demandó al emperador de los persas, llamado Cosroes, que ellos dos, los emperadores, tomaran distancia de sus ejércitos y se enfrentaran el uno contra el otro en un combate singular, y que aquél a quien la victoria fuese otorgada por el altísimo, recibiría el imperio de aquél que fuese vencido, de modo que su pueblo quedase ileso. El rey de los persas indicó su acuerdo y prometió que saldría a batirse en combate singular. El emperador Heraclio tomó sus armas, dejando tras de sí a sus tropas y, cual nuevo

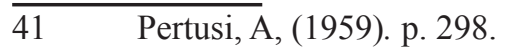

42 Wander, S. H. (1975).

43 Goffart, W. (1963). "The Fredegar Problem Reconsidered", Speculum Vol. 38, N². pp. 206-241; Goffart, W. (2009). "Collins, Roger. Die Fredegar-Chronikon. MGH Studien und Texte vol. 44. Hannover: Hahnsche Buchhandlung, 2007". The Medieval Review. 
David, avanzó para luchar en combate singular. El emperador de los persas, Cosroes, había podido darse cuenta de que uno de sus patricios se destacaba por su bravura en combate: siguiendo lo acordado, lo enviaría a combatir a Heraclio en su lugar.

Uno y otro, a caballo, se acercaron para encontrarse en combate, cuando Heraclio dijo al patricio, que tomaba por Cosroes, el emperador de los persas: Habíamos convenido - dijo - que nosotros debíamos encontrarnos en combate singular: ¿Por qué, entonces, te siguen ellos? En cuanto el patricio giró la cabeza, para ver quién venía detrás de él, Heraclio espoleó violentamente a su caballo con las espuelas, desenvainando un sable y cortando la cabeza del patricio de los persas $^{44}$. El emperador Cosroes, vencido y confundido con los persas, se batió en retirada; luego Cosroes es asesinado por los suyos acorde a sus métodos tiránicos. Los persas, batidos en retirada, regresaron a sus tierras $^{45}$.

El relato de la crónica atribuida a Fredegario es interesante por numerosas razones. En primer lugar, pese a varios detalles, se asemeja bastante al relato de Nicéforo; en segundo lugar es varias décadas anterior al relato de Nicéforo; en tercer lugar, proviene de un ámbito geográfico-cultural alejado de Bizancio; y finalmente, porque establece un vínculo explícito entre la historia del combate de Heraclio y la figura de David. Ahora bien, ¿de dónde provienen las noticias bizantinas de Pseudo-Fredegario? y ¿cuáles son sus fuentes? Algunos han postulado que el cronista franco habría utilizado una fuente bizantina escrita, misma fuente que luego sería utilizada por Nicéforo y quizás por Teófanes. Para otros habría obtenido sus informaciones sobre Oriente a partir de noticias orales, se sabe de contactos entre estas tierras y Bizancio a través de Italia y también de embajadas que iban y venían entre el emperador y los reyes francos, como los contactos que hubo entre el propio Heraclio y el rey Dagoberto ${ }^{46}$. Este

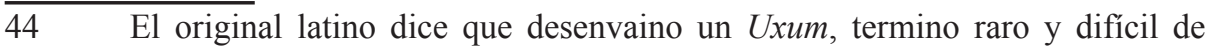
traducir que parece referirse a alguna suerte de hoja curva poco común, Oliver Devillers y Jean Meyers lo traducen como Kandjar para "preservar el exotismo del término". Devillers, O.; Meyers, J. (2001).Frédégaire. Chronique des temps mérovingiens. Turnhout, Brepols, p. 156.

45 Frédégaire. Chronique des temps mérovingiens. pp. 154-157. Traducción propia en colaboración con Juan Pablo Prieto I. a partir de la versión bilingüe latínfrancés de O. Devillers y J. Meyers. Mis agradecimientos a Juan Pablo Prieto.

46 Fischer, A. (2014). "Rewriting History: Fredegar's Perspectives on the Mediterranean". Western Perspectives on the Mediterranean. Bloomsbury, Londres. 
es un asunto debatido por los historiadores, pero antes de pronunciarse sobre el problema es necesario examinar otro testimonio.

En una brevísima nota a pie de página, Wander señala que la Crónica Mozárabe registra el mismo combate que Fredegario. La Crónica Mozárabe o del 754 es una obra historiográfica en latín escrita en la Península Ibérica por un anónimo clérigo mozárabe -cristiano que vive bajo dominio musulmán- cerca del año 754. Esta crónica se centra principalmente en los asuntos hispanos, pero se refiere también a sucesos en el ámbito oriental, árabe y bizantino. La Crónica Mozárabe se inicia hablando del ascenso al poder del emperador Heraclio y, poco más adelante, cuenta que:

Heraclio, después de reunir un ejército, con todo el contingente militar se encamina a Persia para atacarla. Entonces Cosroes, seguro de tal noticia, le sale al encuentro con todo el ejército persa para oponerle resistencia. Cuando Heraclio y Cosroes, exasperados, se encuentran en un punto, establecen un pacto en estos términos: Que elegidos dos guerreros, uno de cada ejército, entablen un combate individual para hacer una prueba con ellos y evaluar cualquier resultado que puedan ver en los mismos, mientras (los dos ejércitos) se mantienen alejados. Hacen tal pacto invocando a la divinidad.

En razón de la fortaleza de estos guerreros y por propia determinación resuelven que cuanto resultase, según hemos dicho, de la suerte manifestada a través de sus espadas, redundase sobre sus compañeros. De esta manera, fiados en sus acuerdos, estarían completamente seguros de que ellos a su vez deberían someter inmediatamente y sin vacilación su orgullo de reyes al yugo del vencedor. Pero Cosroes que era más orgulloso, como es normal entre los filisteos, envió a la lucha a un bastardo, cual otro Goliat. Asustados todos los guerreros de Heraclio vuelven pie atrás. Entonces Heraclio, confiando en el auxilio del Señor, abalanzándose sobre él, lo mata de un solo lanzazo ${ }^{47}$.

pp. 55-75; Herrera Cajas, H. (1998). "Dagoberto y Heraclio, un capítulo de historia diplomática" Dimensiones de la cultura bizantina. Arte, poder y legado histórico. Santiago de Chile, UGM - CEGBN "Fotios Malleros".

47 López Pereira, J.E. (1980). Crónica Mozárabe del 754. Zaragoza, Anubar. 3:1-15. p. 27. 
Este es otro testimonio occidental -posterior a Fredegario pero anterior a Nicéforo- que habla de un duelo por combate entre Heraclio y un guerrero persa en el contexto de la guerra. El relato de la Crónica Mozárabe se asemeja al de Nicéforo al señalar que Heraclio se adelanta ante el miedo de sus hombres y que mata al persa con su lanza, pero también se acerca al de Fredegario pues si bien no habla del emperador como "Nuevo David" compara a su oponente con Goliat. Esto último podría vincularse también con el relato de Teófanes sobre Heraclio abatiendo un guerrero gigante.

¿Cuáles son las fuentes de las noticias orientales en la Crónica Mozárabe? Nuevamente, es un tema complejo y debatido por los historiadores, se han planteado varias fuentes orientales perdidas que podrían ser la base de la crónica hispana, así como de Nicéforo y Teófanes, como por ejemplo una supuesta Chronica Constantinopolitana, una crónica mesopotámica o la historia siria de Teófilo de Edesa, pero los flujos migratorios y comerciales entre Bizancio y la Península Ibérica también hacen posible que esta historia derive de varias noticias dispersas o de una tradición oral ya formada en Bizancio y el Cercano Oriente ${ }^{48}$.

Las menciones a Heraclio en las fuentes occidentales no se agotan aquí, con el tiempo se comenzó a conformar toda una tradición legendaria sobre el emperador bizantino que aparece en sermones religiosos, crónicas, hagiografía e iconografía desde el siglo VII en adelante ${ }^{49}$. Pero lo interesante es que, si se toman en conjunto estas fuentes occidentales "tempranas" y se contrastan con las fuentes bizantinas más "tardías", es casi innegable que existió una importante tradición -histórica o legendaria, aquí no viene al caso- sobre un combate del emperador Heraclio en el contexto de la guerra persa. Esta tradición aparece ya en fuentes de fines del siglo VII, por lo que debe haberse originado en época del propio Heraclio o unas pocas décadas tras su muerte ¿Cuál es la fuente original de donde proviene esta historia? Además de los supuestos poemas perdidos de

$48 \quad$ Dubler, C. E. (1946). "Sobre la Crónica arábigo-bizantina de 741 y la influencia bizantina en la Península Ibérica". Al-Andalus 11. pp. 297-334; López Pereira, J.E. (1980). Estudio Crítico sobre la Crónica Mozárabe del 754. Zaragoza, Anubar. pp.21-36. Vallejo Girvés, M. (2012). Hispania y Bizancio, una relación desconocida. Madrid, Akal.

49 Una homilía -atribuida por algunos a Rábano Mauro- en donde aparece como restaurador de la Santa Cruz, cronistas como Guillermo de Tiro que lo consideran el primer cruzado, un papel importante en la historia de la cruz de la Leyenda Dorada y varias apariciones en la iconografía de la época, ver Baert, B. (2004). A Heritage Of Holy Wood: The Legend Of The True Cross In Text And Image, Brill, Boston. pp. 163-193. Queiroz, G. (2015). "Heraclius, emperor of Byzantium, Revista Digital de Iconografia Medieval, vol. VII, nº 14, pp. 27-38. 
Jorge de Pisidia a los que aludía Wander, existen otras posibilidades. James Howard-Johntson postuló la existencia de una historia oficial de las campañas persas del emperador Heraclio que se habría perdido, pero que sirvió como fuente para obras historiográficas posteriores, y también se ha especulado sobre varias crónicas bizantinas, sirias y persas que no han llegado hasta nosotros, que solo han llegado de forma muy fragmentaria o recogidas en fuentes más tardías, como por ejemplo, una continuación de la crónica de Juan de Antioquía escrita hacia el año $650^{50}$.

La tradición sobre el combate de Heraclio podría haberse originado en cualquiera de estas fuentes escritas perdidas, aunque también es posible que dicha historia se remonte a una tradición oral. Como señalaba Dubler en su estudio sobre las crónicas hispanas, hay evidencia de que los flujos de intercambio en el Mar Mediterráneo nunca fueron cortados completamente por las conquistas islámicas, los hombres seguían circulando y con ellos las noticias, las leyendas y las ideas de toda índole ${ }^{51}$. Incluso, es posible que esta historia formara parte de una tradición oral de poemas o cuentos populares de la época, de esta forma la mención a la "espada de Cosroes" en el poema épico del Diyenís Akrita podría explicarse como un eco de esta tradición oral, que habría sido recogida también en las fuentes escritas previamente analizadas ${ }^{52}$.

En este sentido, la tradición sobre un combate en donde Heraclio se enfrenta a un guerrero persa-al igual que la analogía que muestra a Heraclio como un nuevo David- va mucho más allá de las breves menciones recogidas por Steve H. Wander y criticadas por Ruth E. Leader. Ahora bien, dentro de los Platos de Chipre, el gran plato central no es el único que permite establecer una vinculación con el emperador Heraclio. Dos de los platos menores representan a David luchando contra un león y un oso, tal como se narra en la historia bíblica ${ }^{53}$.

$\overline{50 \quad \text { Sobre la }}$ obra histórica que narraba las campañas de Heraclio: HowardJohnston, J. (1994). "The official history of Heraclius Persian campaigns", The Roman and Byzantine Army in the East, ed. E. Dabrowa, Cracovia. pp. 57-87. Reditadoen: (2006). East Rome, Sasanian Persia and the End of Antiquity. Cornwall, AshgateVariorum. Howards-Johnston especula que el autor de dicha historia podría haber sido el propio Jorge de Pisidia. Sobre otras fuentes de la época supuestamente perdidas: Mango, C. (1990). pp. 12-18. Howard-Johnston. (2010). pp. 244-250. Van Nuffelen, P. (2012). "John of Antioch, inflated and deflated...",Byzantion, 82. pp. 437-450. Hoyland, R. (2011). Theophilus of Edessa's Chronicle and the Circulation of Historical Knowledge.... Liverpool, LUP.

51 Dubler. (1946). pp. 297-334.

52 Castillo Didier, M. (1994). Epopeya de Diyenís Akritas. Santiago, CEBNH "Fotios Malleros". p. 20.

53 Samuel 1, 17:33-37. 


\section{Imagen $2^{54}$}
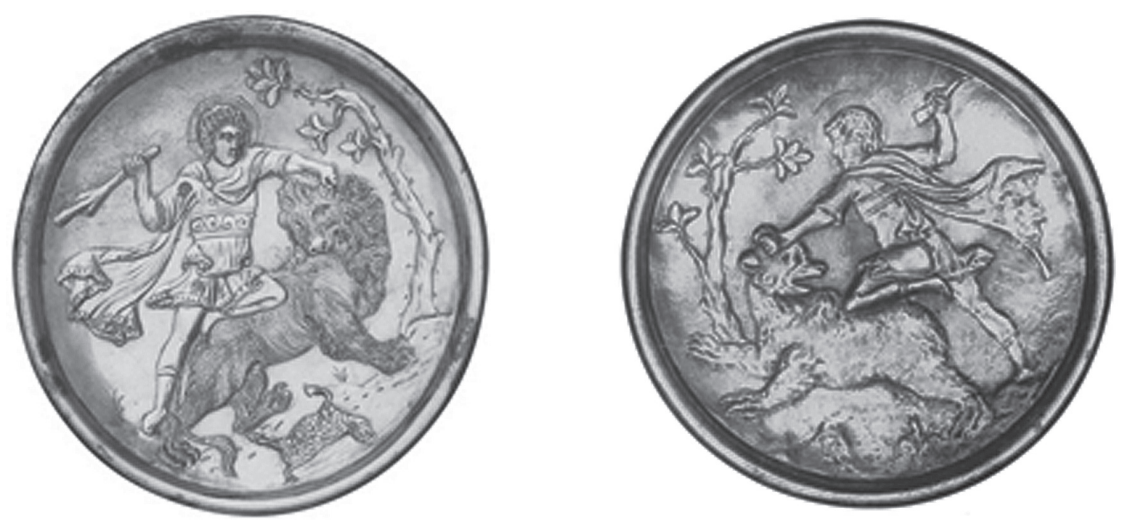

En relación a ello, es curioso que la Crónica de Fredegario -la fuente más antigua que habla del combate- también menciona que Heraclio habría luchado frecuentemente contra leones y jabalíes salvajes ${ }^{55}$. Mas no solo eso, uno de los mayores especialistas en Heraclio, W. E. Kaegi, considera posible que, en su juventud, Heraclio haya luchado contra leones y otras bestias -en situaciones controladas- en las arenas de África, como forma de ganar prestigio entre las tropas de su padre ${ }^{56}$.

Pero además, existe otro paralelismo en las historias de Heraclio y David que podría estar reflejado en los platos, ambos reyes se casaron más de una vez y en circunstancias complejas o cuestionables: David con la mujer de uno de sus soldados y Heraclio con su sobrina. De hecho, según Suzanne Spain las críticas por el matrimonio con su sobrina habrían sido una de las razones por las que el emperador habría querido reforzar el prestigio de su imagen apelando a la figura de David. Pues bien, uno de los platos representa justamente el matrimonio de dicho rey.

54 "David luchando contra un león”.Museo Metropolitano de Nueva York. Código: 17.190.194. "David luchando contra un oso". Museo de Antigüedades, Nicosia, Chipre.Fotos tomadas de Ruth E. (2000). p. 411.

55 Frédégaire. Chronique. pp. 52-53.

56 Kaegi, Walter E. (2003). Heraclius Emperor of Byzantium. Cambridge, CUP. pp. 26-27. El padre de Heraclio - llamado de igual forma- fue exarca de Africa, es justamente desde esta provincia donde comienza la rebelión que pondrá a Heraclio en el trono imperial. 


\section{Imagen $3^{57}$}

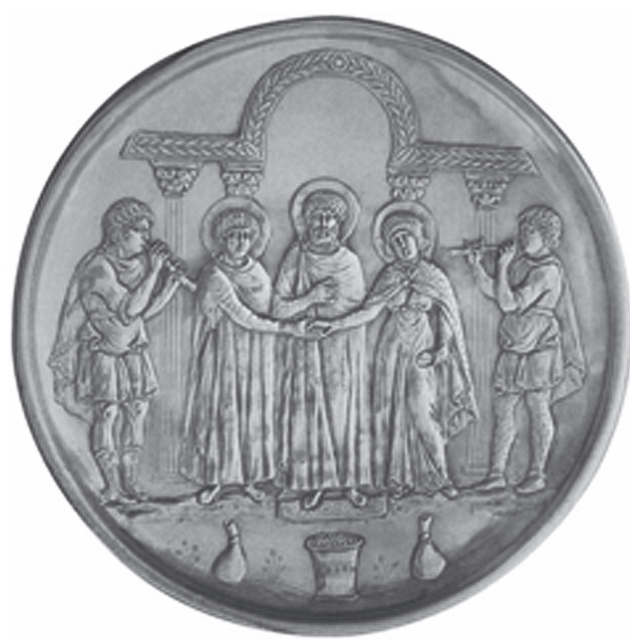

Ahora bien, es verdad que -como señala Leader- no existe ninguna evidencia concreta de que los Platos de Chipre hayan sido encargados por o para el emperador Heraclio - excepto que su factura y costo hacen probable un vínculo con la corte imperial- y también es cierto que en la iconografía de los platos no parecen haber elementos explícitos -indumentaria o signos imperiales- que aludan a la figura de Heraclio. Sin embargo, el peso de la evidencia documental -si se analiza minuciosamente y en conjunto- es demasiado para negarla.

El ambiente de exaltación religiosa de la época de Heraclio, la fuerza que en dicha época tuvo la analogía Heraclio-David, la existencia de una importante tradición -oral o escrita- sobre un combate de Heraclio contra un guerrero persa y otros episodios concretos, como el combate contra fieras o el tema del matrimonio, parecen apuntar en el mismo sentido. Es posible que un análisis minucioso del estilo e iconografía de cada uno de los platos en contraste con las fuentes de la época pueda llegar a encontrar otros puntos de contacto, además de los aquí señalados.

En general, el contraste entre la iconografía y fuentes escritas apunta a que los Platos de David fueron, muy posiblemente elaborados como parte de todo un conjunto de propaganda imperial -historiográfica, literaria y artística-

57 "Matrimonio de David". Museo de Antigüedades, Nicosia, Chipre. Foto tomada de Ruth E. (2000). p. 410. 
de la época que buscaba reforzar el prestigio de Heraclio presentándolo como un "campeón de Dios” y vinculándolo a figuras como David y Constantino.

Además, es necesario considerar el problema sobre la interpretación de las imágenes, cuando se les atribuye a estas un significado ¿Se piensa en aquel que le dio el artista, el mecenas, el público de la época? ¿Heraclio, los clérigos, los nobles de su corte? Aun cuando los Platos de David no hubiesen sido elaborados con la intención de servir como propaganda o aludir al emperador, la imagen que ofrecen las fuentes de la época indica que probablemente mucha gente de la época -y quizás el propio Heraclio- debe haber interpretado estos platos como una alusión en este sentido. Si bien los platos fueron elaborados para banquetes y ceremonias, no sabemos específicamente en qué contextos fueron exhibidos o utilizados en su época, ni tampoco si se siguieron mostrando y utilizando en épocas posteriores, y qué interpretaciones o lecturas recibieron de sus espectadores.

Los historiadores contemporáneos -desde André Grabar hasta Ruth E. Leader- han interpretado estos platos de formas muy diversas, atribuyéndoles una pluralidad de significados: narrativa bíblica, representación histórica, propaganda imperial, objeto ornamental de lujo, representación cristiana moralizante, etc...Pero también las distintas personas de la época debieron haber hecho lo mismo.

Sin duda, los Platos de David no fueron vistos de igual manera ni significaron lo mismo para todos: no tienen por qué haber significado lo mismo para el artesano que los hizo que para la persona que los encargó, de haberlos visto el emperador Heraclio seguramente no los habría interpretado de la misma forma que un clérigo o un soldado.

Los Platos de David pueden haber tenido múltiples niveles de lectura y significación, quizás para algunos se trataría simplemente de un objeto de lujo con valor ornamental, otros habrían leído en el contenido bíblico un mensaje moralizante. Las fuentes aquí analizadas apuntan a que la corte imperial y el círculo cercano a Heraclio probablemente los entendieron como una alusión y exaltación del emperador. Esto no es contradictorio con la apreciación de Ruth E. Leader de que los platos se relacionan a un proceso de cristianización del espacio doméstico. Incluso para una misma persona, estos platos pueden haber significado simultáneamente cosas distintas: objeto de lujo, relato moralizante y alusión al victorioso emperador Heraclio.

Los problemas y debates sobre imágenes como estas derivan, por un lado, de la polisemia de las mismas y, por otro, de aquellos aspectos que simplemente desconocemos sobre ellas. Pero dicha polisemia y preguntas 
abiertas significan también múltiples posibilidades de interpretación, y en ello reside, por tanto, el valor histórico de estas fuentes. Para Bizancio, el siglo VII es una época de profundas transformaciones y documentos siempre insuficientes. Los Platos de David, analizados a la luz de las fuentes escritas, no ofrecen demasiadas certezas pero claramente sugieren interesantes posibilidades.

\section{REFERENCIAS BIBLIOGRÁFICAS}

BAERT, B. (2004). A Heritage Of Holy Wood: The Legend Of The True Cross, Brill, Boston.

BIBLIA DE JERUSALÉN. (1992). Desclee de Brouwer, Bilbao.

CASTILLO DIDIER, M. (1994). Epopeya de DiyenísAkritas. Santiago, CEBNH "FotiosMalleros".

DEVILLERS, O.; MEYERS, J. (2001). Frédégaire. Chronique des temps mérovingiens. Turnhout, Brepols.

DUBLER, C. E. (1946). "Sobre la Crónica arábigo-bizantina de 741 y la influencia bizantina en la Península Ibérica". Al Andalus 11. pp. 297-334.

FISCHER, A. (2014). "Rewriting History: Fredegar's Perspectives on the Mediterranean". Western Perspectives on the Mediterranean. Bloomsbury, Londres. pp. 55-75.

FROLOW, A. (1955). Reserches sur la Déviation de la Ive Croisade vers Constantinople, PUF, París.

GOFFART, W. (1963). “The Fredegar Problem Reconsidered”, Speculum Vol. 38, №2. pp. 206-241. (2009). "Collins, Roger. Die Fredegar-Chronikon. MGH Studien und Texte vol. 44. Hannover: Hahnsche Buchhandlung, 2007”. The Medieval Review.

GRABAR, ANDRÉ. (1936). L'Empereur dans l'art Byzantin, Les Belles Lettres, París. HERRERA CAJAS, H. (1998). "Dagoberto y Heraclio, un capítulo de historia diplomática" Dimensiones de la cultura bizantina. Arte, poder y legado histórico. Santiago de Chile, UGM - CEGBN "FotiosMalleros".

HOWARD-JOHNSTON, J. (1994). "The official history of Heraclius' Persian campaigns", The Roman and Byzantine Army in the East, ed. E. Dabrowa, Cracovia. pp. 57-87. Reditadoen: (2006). East Rome, Sasanian Persia and the End of Antiquity. Cornwall, Ashgate Variorum.

(2010). Witnesses to a world crisis. Historians and Histories of the Middle East in the Seventh Century, New York, Oxford University Press.

HOYLAND, R. (2011). Theophilus of Edessa's Chronicle and the Circulation of Historical Knowledge in Late Antiquity and Early Islam, Liverpool, LUP.

KAEGI, WALTER E. (2003). Heraclius Emperor of Byzantium. Cambridge, CUP. 
LEADER, R. E. (2000). "The David Plates Revisited: Transforming the Secular in Early Byzantium", The Art Bulletin, 82, No. 3, pp. 407-424.

LÓPEZ PEREIRA, J.E. (1980). Estudio Crítico sobre la Crónica Mozárabe del 754. Zaragoza, Anubar.

(1980).Crónica Mozárabe del 754. Zaragoza, Anubar.

MAKK, F. (1975). “Traduction et Commentaire de l'Homélieé crite probablement par Théodore le Syncelle sur le Siège de Constantinople en 626", Acta Universitatis de Attila József Nominatae, Opuscula Byzantina III, Szeged.

MANGO, C; SCOTT, R. (1997) The Chronicle of Theophanes Confessor. Oxford, Clarendon Presss.

(1990). Nikephoros, patriarch of Constantinople, Short History, Washington D.C., Dumbarton Oaks.

MARÍN RIVEROS, J. (2003). Cruzada, guerra santa y yihad. Ed. Universitaria de Valparaíso, Valparaíso.

(2011). "Bizancio en el siglo VII: Entre historia y profecía. Notas en torno a los sucesos del año 626", Byzantion Nea Hellás, 30, pp. 41-73.

MORALES, E.; NORRIS, M.; SCHWARZ, A.; WATTS, E. (2001). A Masterwork of Byzantine Art. The David Plates: The Story of David and Goliath, The Metropolitan Museum of Art, New York.

PERTUSI, A. (1959). Giorgio di Pisidia poemii Panegirici epici, Ettal, BuchKunstverlag.

QUEIROZ DE SOUZA, G. (2015). "Heraclius, emperor of Byzantium, Revista Digital de Iconografia Medieval, vol. VII, no 14, pp. 27-38.

RUNCIMAN, S. (1977). The Byzantine Theocracy, CUP, Cambridge.

SPAIN, S, (1977). "Heraclius, Byzantine Imperial Ideology, and the David Plates", Speculum, 52, No. 2, pp. 217-237.

THOMSON, R.W; HOWARD-JOHNTSON, J. (1999). The Armenian History attributed to Sebeos. Liverpool, Liverpool University Press,

TRILLING, J. (1978). "Myth and Metaphor at the Byzantine Court: A Literary Approach to David Plates", Byzantion, 48, pp. 249-263.

UBIERNA, P. (2002). "La «leyenda del Último Emperador» en Bizancio y el Cercano Oriente cristiano (ss. VII-X). Una instrumentalización del género apocalíptico", Los caminos inexhauribles de la Palabra, Buenos Aires, LUMEN-ISEDET, pp. 463-493.

, P. (2008). "Recherches sur l'apocalyptique syriaque et byzantine au vii siècle: la place de l'Empire romain dans une histoire du salut", Bulletin du centre d'études médiévales d'Auxerre, $\mathrm{n}^{\circ} 2$.

VALLEJO GIRVÉS, M. (2012). Hispania y Bizancio, una relación desconocida. Madrid, Akal.

VAN GRUNSVEN EYGENRAAM, M. (1973). "Heraclius and the David Plates", Bulletin Antieke Beschaving, 48, pp. 158-174. 
VAN NUFFELEN, P. (2012). "John of Antioch, inflated and deflated. Or how (not) to collect fragments of early byzantine historians", Byzantion, 82. pp. 437-450.

WANDER, S. H. (1973). "The Cyprus Plates: The Story of David and Goliath", Metropolitan Museum Journal, 8, pp. 89-95.

(1975). "The Cyprus Plates and the Chronicle of Fredegar", Dumbarton Oaks Papers, 29, pp. 345-346.

WEITZMANN, K. (1970). "Prolegomena to a Study of the Cyprus Plates", Metropolitan Museum Journal, 3, pp. 97-111. 